\title{
Strategi Pengembangan Sektor Industri Alas Kaki Berbahan Kulit dengan Metode Analisis SWOT dan Bisnis Model Canvas
}

\author{
Risma Fitriani $^{1}$, Nugraha ${ }^{2}$, Djamaludin $^{3}$ \\ ${ }^{1}$ Jurusan Teknik Industri, Fakultas Teknik, Universitas Singaperbangsa Karawang \\ J1. HS.Ronggo Waluyo, Puseurjaya, Kec. Telukjambe Timur, Kabupaten Karawang, Jawa Barat 41361 \\ Email: risma.fitriani@ft.unsika.ac.id \\ 2,3 Jurusan Teknik Industri, Fakultas Teknik, Universitas Islam Bandung \\ Jl. Tamansari No.1, Tamansari, Kec. Bandung Wetan, Kota Bandung, Jawa Barat 40116 \\ Email : ${ }^{2}$ nugraha69@unisba.ac.id , ${ }^{3}$ djamaludin@unisba.ac.id
}

\begin{abstract}
ABSTRAK
Dalam beberapa tahun terakhir, pengembangan sub sektor industri dibidang alas kaki berbahan kulit telah diamati di berbagai penjuru dunia, terlebih alas kaki berbahan kulit masuk dalam salah satu industri kreatif sektor fesyen. Indonesia menduduki peringkat keempat sebagai produsen alas kaki di dunia. Untuk mendukung pengembangan industri alas kaki berbahan kulit, penelitian ini bertujuan untuk merancang model bisnis yang sesuai dengan posisi industri alas kaki berbahan kulit saat ini agar lebih tepat sasaran dalam pengembangan industri tersebut. Berdasarkan hal tersebut, metode yang dilakukan adalah dengan menggunakan analisis SWOT untuk mengukur posisi bisnis industri, dan dikombinasikan dengan menggunakan business model canvas $(B M C)$ untuk memetakan model bisnis yang dapat dijadikan pedoman dalam upaya pengembangan industri alas kaki berbahan. Hasil dari penelitian ini diketahui bahwa industri alas kaki berbahan kulit ada pada posisi skor IFE dan EFE matriks yang cukup tinggi, sehingga termasuk pada kategori strategi tumbuh dan membangun, maka ada beberapa alternatif yang tepat untuk posisi bisnis seperti ini, yaitu diantaranya dengan integrasi industri baik secara mundur, maju, maupun horizontal, selain itu dapat dilakukan penetrasi pasar, pengembangan pasar, dan pengembangan produk. Maka dari beberapa alternatif tersebut, dirumuskan rencana pengembangan industri alas kaki berbahan kulit melalui bisnis model canvas yang memetakan 9 blok komponen dalam meningkatkan bisnis.
\end{abstract}

Kata Kunci: SWOT, Business Model Canvas, IFE matriks, IFE matriks

\begin{abstract}
In recent years, the development of industrial sectors in the field of leather-based footwear has been observed in various parts of the world, especially feet of skin made from leather in one of the creative industries of the Fashion sector. Moreover, Indonesia is ranked fourth as a footwear producer in the world. To support the development of the leather-based footwear industri, this study aims to design a business model that is in accordance with the current position of the footwear industri made from today to be more targeted in the development of the industri. Based on this, the method made is to use SWOT analysis to measure the position of industrial business, and combined using the Canvas business model to map a business model that can be used as a guideline in the efforts to develop the footwear industri. The results of this study are known that the leather footwear industri is in the position of the matrix value which is quite high, so that it is included in the growth and constructive strategy category, there are some appropriate tools for business positions like this, namely among them with industrial integration with a backward, Forward, and horizontally, in addition to market penetration, market development, and product development can be done. So from some of these alternatives, the planned development of the leather footwear industri development through the Canvas model business that maps 9 component blocks in increasing business.
\end{abstract}

Keywords: SWOT, Business Model Canvas, matrix Internal-External

\section{Pendahuluan}

Indonesia memiliki banyak sektor Industri kecil dan menengah (IKM) yang telah mampu membuktikan eksistensinya dalam perekonomian Indonesia saat ini. Seperti hal nya ketika krisis moneter melanda Indonesia di tahun 1998, banyak investor dan pengusaha besar yang mengalihkan investasinya ke negara lain. Sehingga perekonomian Indonesia di saat itu semakin terpuruk. Industri kecil dan menengah (IKM) yang mampu bertahan dan menopang roda perekonomian Indonesia [1]. Namun di lain sisi, 
IKM juga menghadapi banyak permasalahan. Seperti: terbatasnya modal kerja, sumber daya manusia yang rendah dan minimnya penguasaan ilmu pengetahuan serta teknologi $[2,3]$. Kendala lain yang dihadapi IKM adalah keterkaitan dengan prospek usaha yang kurang jelas serta perencanaan, visi dan misi yang belum matang $[4,5]$.

Hal ini terjadi karena umumnya IKM bersifat income gathering yaitu menaikkan pendapatan, dengan ciri-ciri sebagai berikut [6,7]: 1) merupakan usaha milik keluarga; 2) menggunakan teknologi yang masih relatif sederhana; 3) kurang memiliki akses permodalan (bankable); 4) dan tidak ada pemisahan modal usaha dengan kebutuhan pribadi, hal tersebut yang merupakan salah satu penghambat IKM dalam persaingannya menghadapi produkproduk impor [8].

Industri alas kaki merupakan salah satu sektor industri non-migas yang diunggulkan oleh Indonesia, karena dapat memenuhi kebutuhan sandang individu, menyerap tenaga kerja yang banyak, serta menyumbang devisa ekspor non-migas yang cukup signifikan bagi negara $[9,10]$. Industri alas kaki berbahan kulit ini juga merupakan salah satu subsektor industri kreatif sector fesyen yanga da di Indonesia. Seperti yang dijelaskan oleh Kemenperin pada tahun 2012, bahwa industri alas kaki adalah salah satu industri yang memiliki peningkatan indeks produksi setiap tahun. [11]. Indeks Produksi Tahunan Berdasarkan data yang diperoleh dari Kementrian Perindustrian Republik Indonesia bahwa pertumbuhan produksi Industri alas kaki di Indonesia terus mengalami peningkatan. Seperti yang dapat dilihat pada Gambar 1 bahwa pertumbuhan produksi di tahun 2012 sebesar $8,89 \%$, pada tahun 2013 sebesar 9,32\%, tahun 2014 pertumbuhannya tidak setinggi pada tahun 2012 dan 2013 yaitu sebesar 3,47\%, dan pada tahun 2015 pertumbuhannya meningkat kembali menjadi $5,19 \%$.

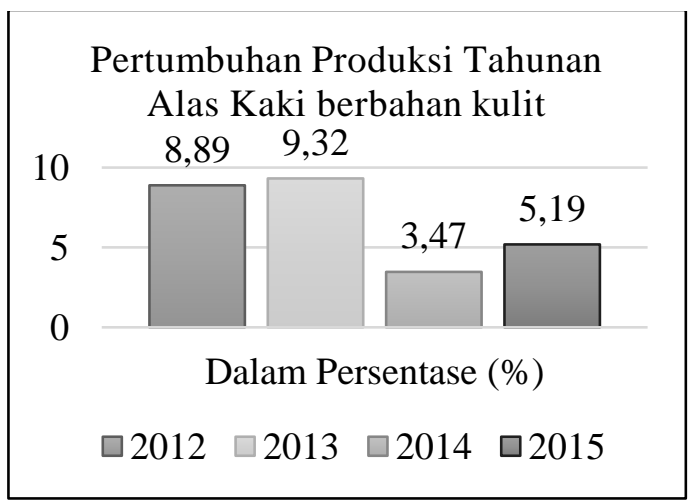

Gambar 1. Pertumbuhan Produksi Tahunan Kulit, Barang dari Kulit dan Alas Kaki Mikro dan Kecil di Indonesia

Tidak berbeda jauh yang terjadi pada tahun 2019, indeks produksi alas kaki berbahan kulit pun mengalami penurunan pada triwulan terakhir seperti yang dtunjukkan pada Gambar 2, dimana peningkatan indeks hanya terjadi pada triwulan kedua, sedangakn terus menurun pada triwulan ketiga dan keempat. Hal ini tentu saja membutuhkan perhatian khusus, mengingat bahwa industri alas kaki Indonesia merupakan produsen keempat di dunia. Dan sangat disayangkan jika terus dibiarkan tanpa memiliki strategi pengembangan bisnis yang tepat.

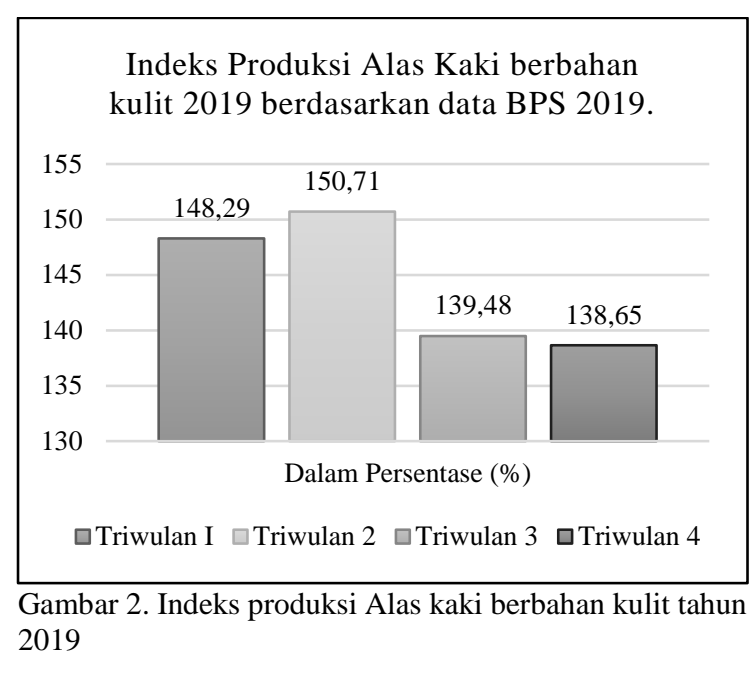

Daerah yang memiliki potensi yang besar dalam pengembangan sentra produksi alas kaki di Indonesia adalah Jawa Barat dan Jawa Timur. Hal ini dilihat dari jumlah unit usaha dan penyerapan tenaga kerjanya. Jawa Barat dan Jawa timur memiliki sentra alas kaki yang cukup besar di Indonesia. Penelitian ini bertujuan untuk menganalisis potensi pengembangan industri alas kaki berbahan kulit di Jawa Barat melalui analisis SWOT yaitu untuk memahi kelebihan kelemahan, peluang dan ancaman yang dihadapi sektor industri alas kaki berbahan kulit, selain itu dilakukan juga analisis posisi bisnis industri ini agar diperloleh strategi yang tepat dalam upaya pengembangan model bisnis industri alas kaki berbahan kulit ini. Setelah itu, berdasarkan hasil analisis, akan dirancang model bisnis canvas guna memetakan komponen-komponen pengembangan seperti apa yang akan diperlukan oleh para pelaku industri alas kaki berbahan kulit ini. Penelitian ini diharapkan dapat memberi solusi bagi pelaku industri alas kaki berbahan kulit di Indonesia. Selain itu untuk meningkatkan upaya bisnis mereka menjadi lebih baik.

Dalam merancang bisnis model canvas pada sector industri alas kaki berbahan kulit ini, ada beberapa tahapan yang harus dijalankan, yaitu melakukan input berbagai informasi mengenai kondisi yang sedang dihadapi oleh pelaku industri alas kaki berbahan kulit yang tersebar di Indonesia, namun karena pelaku industri ini mayoritas berada di Jawa Barat dan Jawa Timur, maka fokus analisis ini dilakukan pada kedua lokasi industri di daerah tersebut. Analisis yang diambil sebagai dasar pengambilan keputusan pada penelitian ini adalah analsiis SWOT, dimana SWOT adalah sebuah 
analisis yang di dalamnya berfokus pada kondisi bisnis dalam menilai empat pertanyaan besar, yakni apa saja kekuatan yang dimiliki sector industri alas kaki berbahan kulit, lengkap dengan kelemahannya, kedua hal ini digunakan untuk meniali kondisi internal dari sector industri alas kaki berbahan kulit ini, selain itu dilakukan juga penilaian organisasi dalam lingkungan yang luas dengan memahami peluang apa saja yang dimiliki serta ancaman yang dihadapi oleh industri tersebut untuk mampu berkembang. [5].

Setelah diketahui keempat hal dalam SWOT, maka berikutnya dilakukan perhitungan untuk mengevaluasi kondisi internal dan kondisi eksternal dari sektor industri tersebut yang biasa dikenal dengan matriks internal factor evaluation (IFE) dan matriks external factor evaluation (EFE). Matriks IFE adalah perangkat formulasi untuk melakukan evaluasi terhadap faktor kekuatan dan kelemahan utama pada fungsi bisnis sector industri alas kaki berbahan kulit saat ini dan juga memberikan dasar-dasar untuk melakukan identifikasi serta evaluasi antar fungsi bisnis yang dijalankan oleh sector industri alas kaki berbahan kulit [4]. Matriks EFE adalah kumpulan faktorfaktor dari sudut pandang ekonomi, sosial, budaya, lingkungan, politik, pemerintahan, hukum dan teknologi yang sesuai dengan kondisi sector industri alas kaki berbahan kulit saat ini [4]. Tahapan berikutnya adalah menggunakan hasil dari matrik IFE dan EFE tersebut sebagai dasar pemetaan posisi bisnis sector industri ini dengan menggunakan matriks internal [4].

Selain memperoleh nilai matrik internal dan eksternal sebagai bentuk analisis situasi sector industri alas kaki berbahan kulit, berikutnya adalah mengukur posisi sector industri ini dengan menilai aspek financial position (FP), Industri Position (IP), Stability Position (SP), dam Competitive position (CP), dimana dari hasil ini akan diketahui strategi profil sector industri apa yang terjadi, baik agresif, konservatif, kompetitif, atau desensif.

Berdasarkan hasil analisis diatas, hal terakhir yang dilakukan adalah menyusun business model canvas (BMC) dimana di dalamnya terdapat 9 komponen inti yang harus disesuaikan dengan kondisi sector industri alas kaki berbahan kulit agar menunjang pengembangan sector ini.

BMC merupakan salah satu media yang digunakan untuk mendukung tercapainya strategi pengembangan sector industri alas kaki berbahan kulit berdasarkan arah pengembangan yang ditetapkan pemerintah. Sehingga BMC ini menajdi salah satu sarana untuk mencapai tujuan pengembangan sector industri tersebut [12]. BMC digunakan sebagai salah satu bisnis model yang dengan sederhana mampu merumuskan, mengimplementasi serta mengevaluasi komponen- komponen lintas fungsional yang memampukan setiap organisasi mencapai tujuannya [13].

Analisis BMC adalah digunakan sebagai model analisis yang menjabarkan pemikiran mengenai bagaimana sector industri alas kaki berbahan kulit dapat menciptakan, memberikan, dan menangkap nilai yang dimiliki dari sebuah organisasi [14]. Namun terdapat kelemahan seperti diabaikannya tujuan strategis dari organisasi, tidak menyinggung adanya suatu kompetisi, serta tidak ada penetapan prioritas dalam model bisnisnya [9]. Melalui pendekatan ini, akan ditampilkan 9 elemen yang terdapat pada model bisnis dalam 9 kotak. Berikut ini adalah elemen-elemen BMC beserta penjelasannya [14]:

1. Segmentasi Pelanggan (Customer Segment) menjelaskan kelompok-kelompok orang atau organisasi yang ingin dicapai oleh sector industri alas kaki berbahan kulit.

2. Proposisi Nilai (Value Propositions) menjelaskan suatu rangkaian produk alas akki berbahan kulit yang akan dipasarakn kepada konsumen. Nilai tersebut dapat berwujud kuantitatif (contohnya: harga, kecepatan layanan) atau kualitatif (contohnya: desain, pengalaman pelanggan).

3. Saluran (Channels) dibedakan menjadi langsung dan tidak langsung, sebagaimana juga dibedakan menjadi channel milik sendiri dan channel milik partner. Channel milik sendiri yang bersifat langsung contohnya in-house sales dan website. Sedangkan channel milik sendiri yang bersifat tidak langsung, contohnya retail. Channel milik partner bersifat tidak langsung dan memungkinkan perusahaan untuk memperluas jangkauan dan manfaat dari kekuatan partner. Contohnya grosir, retail, atau web sites milik partner.

4. Hubungan Pelanggan (Customer Relationship) mendeskripsikan tentang berbagai tipe hubungan yang diciptakan oleh pelaku sector industri alas kaki berbahna kulit dengan segmen pelanggan yang spesifik. Customer relationship dapat dipengaruhi oleh berbagai motif, yaitu customer acquisition, customer retention, boosting sales (upselling).

5 Aliran Pendapatan (Revenue Streams) mendeskripsikan aliran kas yang didapatkan oleh pelaku sector industri alas kaki berbahna kulit dari masing-masing segmen pelanggan. Dimana dari analisis ini dapat menghasilkan dua jenis aliran pendapatan, yaitu transaction revenues dan recurring revenue.

6. Sumber Daya Utama (Key Resources) menjelaskan aset-aset yang dimiliki sector industri alas kaki berbahan kulit secara umum agar model bisnis dapat bekerja. 
7. Aktivitas Utama (Key Activites) menjelaskan aktivitas utama yang dilakukan sector industri alas kaki berbahan kulit agar model bisnisnya bekerja dengan baik. Seperti halnya sumber daya utama, aktivitas utama juga dibutuhkan untuk menciptakan nilai, mencapai pasar, mempertahankan customer relationship, dan menerima pendapatan.

8. Kemitraan Utama (Key Partnerships) mendeskripsikan jaringan para supplier dan mitra yang membuat model bisnis berjalan. Para pelaku sector industri alas kaki berbahan kulit ini melakukan kemitraan untuk berbagai tujuan, dan kemitraan telah menjadi landasan pada banyak model bisnis untuk mengoptimalkan model bisnis yang dijalankan, mengurangi risiko, dan memperoleh sumber daya.

9. Struktur Biaya (cost structure) mendeskripsikan semua biaya yang terjadi untuk menjalankan model bisnis pada sector industri alas kaki berbahan kulit ini.

SWOT dan BMC memiliki keunggulan masing-masing yang saling melengkapi dalam membentuk sebuah model bisnis, dimana dengan menggunakan keduanya akan mampu menggambarkan secara sederhana dan menyeluruh terhadap kondisi sector industri alas kaki berbahan kulit saat ini berdasarkan beberapa komponen BMC, baik segmen konsumen, value yang ditawarkan, channel, hubungan dengan pelangan, aliran pendapatan, aset vital, mitra kerja sama, serta struktur biaya yang dimiliki sektor ini $[15,16,17$, 18].

Berdasarkan beberapa penelitian sebelumnya, ada berbagai jenis pengelompokkan dalam masingmasing komponen pada pemetaan BMC, diantaranya yaitu pada komponen segmentasi pelanggan terdapat berbagai tipe customer segment yaitu mass market, niche market, segmented, diversified, multi-sided platform [19, 20]. Untuk komponen proposisi nilai terdapat macam-macam nilai diantaranya newness, performance, customization, getting the job done, design, brand/status, price, cost reduction, risk reduction, accessibility, convenience/usability [21, 22].

Pada komponen Saluran (Channel) terdiri dari beberapa jenis fase saluran, yakni fase awareness, evaluation, purchase, delivery, dan aftersales [23, 24]. Komponen berikutnya adalah hubungan pelanggan yang dapat dikategorikan menjadi personal assistance, dedicated personal assistance, self-service, automated service, cocreation, dan communitites [25, 26]. Pada komponen aliran pendapatan, terdapat 2 tipe mekanisme pemberian harga, yaitu pemberian harga tetap dan harga dinamis [27]. Komponen sumber daya utama dapat dikategorikan menjadi fisik, intelektual, manusia, dan finansial [28].
Pada komponen aktivitas utama dapat dibedakan menjadi produksi, pemecahan masalah, dan platform/network [29]. Komponen kemitraan utama dapat dibedakan menjadi beberapa jenis, yaitu aliansi strategis diantara para perusahaan bukan pesaing, kemitraan strategis diantara perusahaan pesaing, joint ventures untuk mengembangkan bisnis baru, hubungan pembeli-supplier untuk memastikan bahan-bahan suplai yang terjamin [30]. Dan komponen struktur biaya secara umum mempunyai dua jenis struktur biaya, yaitu cost-driven dan valuedriven [31].

Hal-hal tersebut adalah beberapa aspek yang dapat dipertimbangkan dalam menyusun 9 komponen pada bisnis model canvas di sector industri alas kaki berbahan kulit.

\section{Metode Penelitian}

Penelitian ini termasuk dalam penelitian kuantitatif, dimana analisis dilakukan berdasarkan evaluasi hasil perhitungan banyak aspek. pengumpulan data dilakukan dengan cara memulai analisis SWOT melalui identifikasi empat aspek yakni kekuatan, kelemahan, peluang dan ancaman yang dihadapi oleh para pelaku usaha alas kaki berbahan kulit, serta ditunjang dengan data dari kementerian pariwisata dan ekonomi kreatif. selanjutnya melakukan perhitungan pembobotan faktor internal dan faktor eksternal dari keempat aspek tersebut dengan menggunakan matriks Internal Factor Evaluation (IFE) dan Matriks External Factor Evaluation (EFE). Dari hasil pengolahan tersebut akan diketahui score masingmasing aspek dan akhirnya dapat dihitung nilai pembobotan untuk mengetahui dimana posisi industri alas kaki berbahan kulit berada dari pandangan kuadran matrik IE dan jenis profil strategi yang terjadi apda sector industri alas kaki berbahan kulit.

Tahap selanjutnya, berdasarkan analisis posisi industri alas kaki berbahan kulit pada kuadran matriks, maka dilakukan pengembangan strategi sesuai dengan prioritas posisi kuadran yang telah didapat dengan menggunakan Business Model Canvas (BMC).

Analisis BMC digunakan untuk menjabarkan pemikiran mengenai bagaimana para pelaku sector industri alas kaki ebrbahan kulit ini dapat menciptakan, memberikan, dan menangkap nilai yang dimiliki [14]. Namun karena terdapat kelemahan seperti diabaikannya tujuan strategis dari organisasi, tidak menyinggung adanya suatu kompetisi, serta tidak ada penetapan prioritas dalam model bisnisnya [9], maka dengan adanya kombinasi dengan analisis SWOT di awal penelitian, diharapkan mampu melengkapi kebutuhan strategi bisnis yang tepat dalam mendukung pengembangan sektor industri alas kaki berbahan kulit tersebut. 


\section{Hasil dan Pembahasan}

Berdasarkan hasil pengumpulan data dari berbagai responden, maka diperoleh skor faktor internal (IFE) seperti yang ditunjukkan pada Tabel 1, sementara untuk skor faktor eksternal (EFE) ditunjukkan pada Tabel 2, dan nilai akhir dari perbandingan skor internal-eksternal ditunjukkan dengan matriks pada Tabel 3. Serta hasil strategi SWOT berdasarkan perhitungan kuadran ditunjukkan pada gambar 3 .

Tabel 1. Hasil Internal Factor Evaluation (IFE)

\begin{tabular}{|c|c|c|c|}
\hline IFE & Bobot & Rating & Score \\
\hline \multicolumn{4}{|l|}{ Kekuatan } \\
\hline Bahan kulit di Indonesia termasuk salah satu yang terbaik. & 0,069 & 4,2 & 0,290 \\
\hline Tenaga kerja melimpah. & 0,054 & 3,3 & 0,179 \\
\hline $\begin{array}{l}\text { Banyaknya komunitas UMKM sehingga mampu mendorong } \\
\text { pemasaran. }\end{array}$ & 0,049 & 3,0 & 0,143 \\
\hline $\begin{array}{l}\text { Banyaknya perancang yang berkompeten dan bermutu dimiliki } \\
\text { negeri ini. }\end{array}$ & 0,047 & 2,9 & 0,136 \\
\hline $\begin{array}{l}\text { Mulai banyaknya inovasi dan teknologi bahan baku yang } \\
\text { berkembang. }\end{array}$ & 0,062 & 3,8 & 0,233 \\
\hline Adanya akademi teknik kulit memperkuat pengelolaan industri. & 0,057 & 3,4 & 0,195 \\
\hline Meningkatnya teknologi media sosial. & 0,049 & 3,0 & 0,148 \\
\hline Jumlah produsen yang cukup banyak. & 0,048 & 2,9 & 0,141 \\
\hline Produk memiliki daya saig yang kuat disarana domestik. & 0,053 & 3,2 & 0,168 \\
\hline Semakin terbukanya jalur distribusi produk ke pasaran dunia. & 0,046 & 2,8 & 0,127 \\
\hline Total kekuatan & 0,534 & & 1,761 \\
\hline \multicolumn{4}{|l|}{ Kelemahan } \\
\hline Masih kurang tingginya kualitas tenaga kerja & 0,057 & 3,5 & 0,199 \\
\hline $\begin{array}{l}\text { Pada produsen masih kurang memiliki pandangan business value } \\
\text { yang nyata. }\end{array}$ & 0,057 & 3,5 & 0,198 \\
\hline Daya saing pasar global masih rendah. & 0,064 & 3,9 & 0,248 \\
\hline Kurang tergalinya potensi budaya lokal sebagai bagian dari inovasi. & 0,060 & 3,7 & 0,219 \\
\hline Teknologi penyamakan kulit masih tergolong rendah. & 0,049 & 3,0 & 0,145 \\
\hline Regulasi tenaga kerja yang masih kurang nyaman. & 0,050 & 3,0 & 0,152 \\
\hline Konektivitas antar kelompok usaha serupa masih minim. & 0,068 & 4,1 & 0,279 \\
\hline Pembiayaan belum memiliki skema yang tepat. & 0,062 & 3,8 & 0,231 \\
\hline Total kelemahan & 0,466 & & 1,672 \\
\hline Total keseluruhan Kekuatan dan Kelemahan & $\mathbf{1 , 0 0 0}$ & & $\mathbf{3 , 4 3}$ \\
\hline
\end{tabular}

Tabel 2. Hasil Eksternal Factor Evaluation (EFE)

\begin{tabular}{llcc}
\hline \multicolumn{1}{c}{ EFE } & Bobot & Rating & Score \\
\hline Peluang & & & 0,502 \\
\hline Masih terbukanya potensi pasar domestik. & 0,114 & 4,4 & 0,493 \\
Pasar luar negeri masih terbuka luas. & 0,113 & 4,4 & 0,235 \\
Sharing knowledge yang semakin berkembang. & 0,078 & 3,0 & 0,256 \\
Mulai terbukanya jalur distribusi yang lebih luas. & 0,081 & 3,2 & 0,268 \\
Potensi pemasaran melalui media sosial tergolong menjanjikan. & 0,083 & 3,2 & 2,090 \\
\hline Total Peluang & 0,559 & & 0,243 \\
\hline Ancaman & & 0,438 \\
Kurangnya apresiasi pasar. & 0,079 & 3,1 & 0,361 \\
Adanya produk asing yang semakin gencar dipasarkan. & 0,106 & 4,1 & 0,302 \\
Minimnya pemahaman mengenai konsumen luar negeri. & 0,097 & 3,7 & 1,602 \\
Bermunculannya pasar asing di dalam negeri. & 0,088 & 3,4 & $\mathbf{3 , 6 9 1}$ \\
\hline Total Ancaman & 0,441 & & $\mathbf{1 , 0 0 0}$ \\
\hline Total Keseluruhan Peluang dan Ancaman & & & \\
\hline
\end{tabular}

Tabel 3. Hasil Internal-Eksternal Matriks (IE)

\section{Internal-Eksternal Matriks}

Tinggi
$3,00-4,00$




\begin{tabular}{|c|c|c|c|c|c|}
\hline \multirow{3}{*}{ EFE Score } & Tinggi & $3,00-4,00$ & $\begin{array}{l}\text { Tumbuh dan } \\
\text { Membangun }\end{array}$ & $\begin{array}{l}\text { Tumbuh dan } \\
\text { Membangun }\end{array}$ & $\begin{array}{l}\text { Bertahan dan } \\
\text { Memperbaiki }\end{array}$ \\
\hline & Medium & $2,00-2,99$ & Tumbuh dan & Bertahan dan & Panen atau \\
\hline & Rendah & $1,00-1,99$ & $\begin{array}{l}\text { Bertahan dan } \\
\text { Memperbaiki }\end{array}$ & $\begin{array}{c}\text { Panen atau } \\
\text { Berhenti }\end{array}$ & $\begin{array}{c}\text { Panen atau } \\
\text { Berhenti }\end{array}$ \\
\hline
\end{tabular}

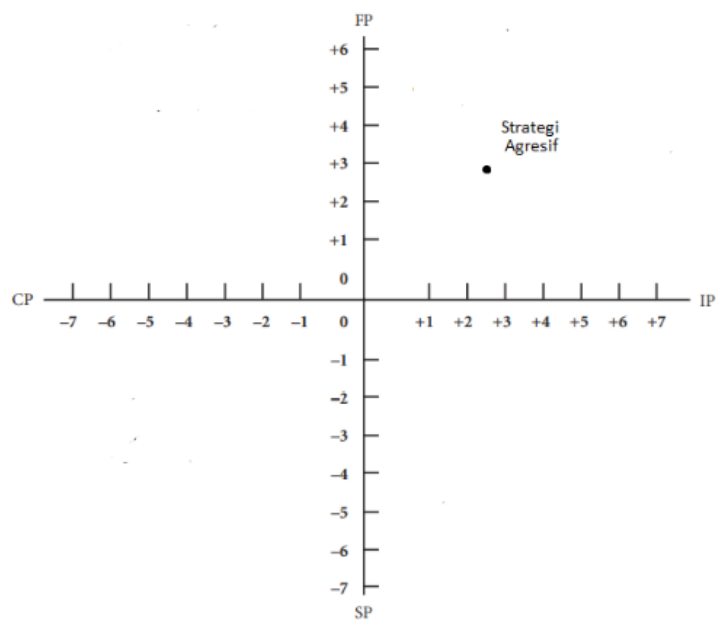

Gambar 3. Kuadran strategi SWOT

Tabel 1 menjelaskan bahwa kekuatan tersebar industri alas kaki berbahan kulit di Indonesia adalah bahan baku kulit yang berkualitas dan mampu bersaing di pasaran duani akrena merupakan salah satu bahan kulit terbaik. Sedangkan kelemahan dari industri ini sendiri adalah kurangnya koneksi dan kerjasama antar para pelaku usaha industri alas kaki berbahan kulit ini.

Selain itu, Tabel 2 menjelaskan bahwa industri alas kaki berbahan kulit ini memiliki peluang bersar pada sasaran penjualan, akrena pasar domestic maupun internasioanl masih terbuka luas.

Dan Tabel 3 menjelaskan bahwa posisi industri alas kaki berbahan kulit memiliki skor di atas 3, yakni artinya bertumbuh dan membangun, dimana pada skema ini, ada beberapa alternatif strategi yang dapat dikembangkan dengan bisnis model canvas, diantaranya integrasi bisnis secara mundur, maju maupun horizontal, penetrasi pasar, pengembangan produk, dan pengembangan pasar. $[4,5]$.

Gambar 3 menujukkan berdasarkan hasil perhitungan yang diperoleh, profil strategi yang diterapkan pada sektor industri alas kaki berbahan kulit adalah startegi agresif, hal ini sejalan dengan hasil perhitungan yang diperoleh dari matriks IFE dan EFE, dimana alternatif yang dapat dilakukan adalah integrasi industri baik secara mundur, maju, maupun horizontal, selain itu dapat dilakukan penetrasi pasar, pengembangan pasar, dan pengembangan produk.
Maka setelah diketahui kondisi bisnis dan strategi yang dapat dilakukan, tahapan terakhir yang dilakukan adalah menyusun rancangan business model Canvas sesuai dengan strategi yang diperlukan ditunjukkan pada Gambar 4.

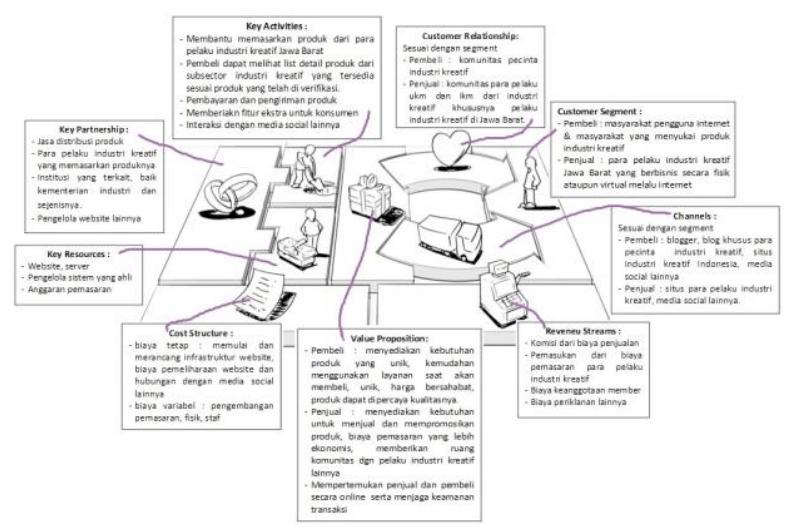

Gambar 4. Rancangan Business Model Canvas Industri Alas Kaki Berbahan Kulit

Berdasarkan gambar 4, telah dipetakan 9 komponen dalam rancangan business model canvas pada industri alas kaki berbahan kulit, berikut penjelasan dari masing-masing komponen tersebut.

1. Customer Segment

Dalam sektor industri alas kaki berbahan kulit, konsumen dikelompokkan berdasarkan adanya kebutuhan, perilaku dan atribut yang sama sehingga dapat dipahami kebutuhan konsumen tersebut. Dalam hal ini yang dimaksud konsumen adalah:

a. Pembeli : masyarakat pengguna internet \& masyarakat yang menyukai produk industri alas kaki berbahan kulit

b. Penjual : para pelaku industri alas kaki berbahan kulit yang menjual produknya dan mau berbisnis secara fisik taupun virtual melalu internet.

\section{Value Propositions}

Value propositions sendiri adalah berbagai macam produk dan jasa karya industri alas kaki berbahan kulit yang akan menciptakan nilai bagi pembeli, dan value propositions menjadi alasan mengapa pembeli harus mempertimbangkan untuk memilih produk dan jasa dari sector industri alas kaki berbahan kulit yang ditawarkan dalam bisnis model ini. Dalam hal ini, value proposition yang ditawarkan adalah produk industri alas kaki berbahan kulit yang berkualitas, dimana setiap produk yang dipasarkan telah di nilai sebelumnya untuk 
dinilai kelayakannya dipasarkan pada masyarakat umum, sehingga produk yang dipasarkan pun merupakan produk yang berkualitas.

Selain itu biaya yang dikeluarkan akan jauh lebih ringan karena produk dipasarkan secara langsung dan luas pada konsumen tanpa banyak perantara, sehingga memudahkan konsumen untuk memilih produk alas kaki kulit yang sesuai dengan keinginannya.

Dari jenis bisnis ini, value yang ditawarkan adalah:

a. Bagi pembeli : pelauku usaha industri ini menyediakan kebutuhan produk alas kaki kulit, kemudahan memperoleh layanan penjualan saat akan membeli, harga bersahabat, produk dapat dipercaya kualitasnya.

b. Bagi penjual : adanya system untuk mendukung kebutuhan dalam menjual dan mempromosikan produk yang diproduksinya, biaya pemasaran yang lebih ekonomis, memberikan ruang komunitas pada pelaku usaha alas kaki sejenis.

c. Selain itu perusahaan juga memberikan keleluasaan penjual dan pembeli untuk bertemu secara online dengan memberi keamanan dalam bertransaksi.

\section{Channels}

Channels adalah suatu media dari para pelaku industri alas kaki berbahan kulit dalam melakukan komunikasi untuk mencapai para pelanggannya dalam menyampaikan nilai-nilai yang dimiliki. Dimana para pelaku usaha diberikan keleluasaan untuk memperkenalkan dan mempromosikan produk yang dihasilkannya, serta memberikan kemudahan pada para pelaku industri dengan konsumen untuk memperoleh jalur jual-beli yang tidak terlalu rumit dan sulit. Sehingga dengan demikian, adanya model bisnis ini dapat menunjang segment yang akan dicapai. Channel dalam hal ini diantaranya:

a. Dari segi segmen Pembeli : blogger, market place seperti tokopedia, shoppe, blibli.com, lazada, Zalora, bukapalak, jd.id, forum jual beli, blog khusus para pecinta industri kreatif, khususnya industri alas kaki berbahan kulit, situs industri kreatif Indonesia, media social dan marketplace lainnya.

b. Dari segi segmen Penjual : situs para pelaku industri kreatif, media social, marketplace tokopedia, shoppe, blibli.com, lazada, Zalora, bukapalak, jd.id, forum jual beli, channel bahan baku dan lainnya.

\section{Customer Relationship}

Customer relationship ini menjelaskan jenis hubungan para pelaku industri alas kaki berbahan kulit dengan segmen pelanggan yang akan dicapainya. Dalam hal ini pihak-pihak yang menunjang pada segment yang akan dituju, diantaranya: a. Untuk segment Pembeli : berhubungan dengan komunitas pecinta industri berbahan kulit

b. Untuk segment Penjual : berhubungan dengan komunitas para pelaku ukm dan ikm dari sektor industri khususnya industri alas kaki berbahan kulit.

\section{Revenue Streams}

Komponen ini menjelaskan mengenai kas yang dihasilkan oleh sector industri alas kaki berbahan kulit karena telah mempertemukan antara penjual dan pembeli sehingga dapat memenuhi kebutuhan pemasaran guna meningkatkan pengembangan sector industri ini. Pendapatan dalam hal ini diperoleh dari:

a. Komisi dari biaya penjualan.

b. Pemasukan dari biaya pemasaran para pelaku industri kreatif alas kaki berbahan kulit.

c. Biaya keanggotaan member.

d. Biaya periklanan lainnya

6. Key Resources

Menjelaskan beberapa jenis sumber daya yang penting untuk dimiliki agar model bisnis pada industri alas kaki berbahan kulit ini dapat berjalan dengan lancar. Key resources dalam hal ini adalah:

a. Website, server, marketplace

b. Pengelola sistem yang ahli.

c. Anggaran pemasaran

7. Key Activities

Kegiatan utama dalam model bisnis ini dibutuhkan untuk memasarkan dan mendistribusikan value proposition yang telah dijelaskan sebelumnya yaitu produk hasil industri alas kaki berbahan kulit yang berkualitas agar dapat memasuki pasar, memelihara hubungan dengan pembeli dan para pelaku industri dapat memperoleh pendapatan sehingga dapat mendukung pengembangan sector industri ini. berikut paparan aktivitas utama yang dijalankan adalah:

a. Membantu memasarkan produk dari para pelaku industri alas kaki berbahan kulit sesuai wilayahnya masing-masing melalui berbagai marketplace.

b. Pembeli dapat melihat list detail produk dari sector industri alas kaki berbahan kulit yang tersedia.

c. Pembayaran dan pengiriman produk.

d. Memberikan fitur ekstra untuk konsumen seperti pelayanan servis kulit alas kaki.

e. Semua kegiatan mencakup dari hulu ke hilir industri alas kaki berbahan kulit

f. Interaksi dengan komunitas dan media sosial lainnya.

8. Key Partnership

Komponen ini menjelaskan jaringan kerjasama antar para pelaku industri alas kaki berbahan kulit dengan pihak lain yang telibat dalam berjalannya bisnis tersebut, dalam hal ini yang terlibat adalah: 
a. Supplier bahan baku

b. Jasa distribusi produk.

c. Para pelaku industriyang memasarkan produknya.

d. Institusi yang terkait, baik kementerian industri dan sejenisnya.

e. Pengelola website, marketplace dan lainnya.

9. Cost Structure

Menjelaskan jenis biaya yang dikeluarkan untuk menjalankan sector industri alas kaki berbahan kulit pada sebuah bisnis. Dalam hal ini, ada 2 jenis biaya yang dikeluarkan,yaitu:

a. Biaya tetap : produksi, distribusi, perancangan infrastruktur website, biaya pemeliharaan website dan hubungan dengan media social/marketplace lainnya.

b. Biaya variabel : biaya pengembangan industri, pemasaran, fisik, maupun tenaga kerja.

\section{Kesimpulan}

Berdasarkan hasil analisis dalam penelitian ini, diketahui bahwa industri alas kaki berbahan kulit berada pada posisi skor internal dan eksternal yang tinggi, dan berda pada profil strategi agresif, maka hal yang harus dilakukan adalah tumbuh dan membangun pengembangan industri yang lebih kuat, melalui beberapa strategi yang dpaat diterapkan, diantaranya dengan integrasi mundur, maju, atau horizontal, penetrasi pasar, pengembangan Pasar, dan Pengembangan produk. Selain itu perlu juga memperhatikan kemajuan teknologi dalam mengembangan bisnis model kanvas agar semua kebutuhan dapat terintegrasi dengan baik.

Penelitian ini tidak lepas dari keterbatasan, dimana pada penelitian ini, responden dibatasi 100 responden yang merupakan perwakilan dari para pelaku usaha alas kaki berbahan kulit di beberapa wilayah. Kedepannya dapat dilakukan dengan melibatkan lebih banyak lagi responden dan para pengamat bisnis. Selain itu penelitian ini juga belum menghubungan kapabilitas para pelaku usaha dalam membangun bisnis agar lebih baik lagi.

\section{Daftar Pustaka}

[1] G. S. A. Putra dan N. Maulana, "Strategi Meningkatkan Daya Saing Industri Kreatif Indonesia: Studi Kasus Pengembangan Klaster Industri Alas Kaki Kecamatan Tamansari, Bogor," Ultima Management, vol. X, no. 2, pp. 97-109, 2018.

[2] Sudaryanto dan A. Hanim, "Evaluasi Kesiapan UKM Menyongsong Pasar Bebas
Asean (APTA): Analisis Perspektif dan Tinjauan Teoritis," Jurnal Ekonomi Akuntansi dan Manajemen, vol. I, no. 2, pp. 189-193, 2002.

[3] F. L. Z. Bonazzi dan M. A. Zilber, "Innovation and Business Model: A Case Study about Integration of Innovation Funnel and Business Model Canvas," Organizational Strategy and Behavior, vol. XVI, no. 53, pp. 616-637, 2014.

[4] F. R. David, Strategic Management Concepts and Cases, New York City: Pearson Prentice Hall Inc., 2006.

[5] F. Rangkuti, Analisis SWOT Teknik Membedah Kasus Bisnis, Jakarta: PT. Gramedia Pustaka Utama, 2000.

[6] Jogiyanto, Sistem Informasi Strategik untuk Keunggulan Kompetitif, Yogyakarta: Andi Offset, 2005.

[7] S. Blank dan B. Dorf, The Starup Owner's Manual The Step-by-Step Guide for Building a Great Company, California: K and S Ranch Inc., K\&S Ranch Publishing Division, 2012.

[8] A. Payne, Service Marketing, Yogyakarta: Andi, 2000.

[9] D. Adhitya dan M. Eka, “Analisis Model Bisnis pada Bisnis Sepatu Guten.Inc Menggunakan Model Bisnis Kanvas,' Jurnal Sosioteknologi, vol. XV, no. 3, pp. 323-334, 2016

[10] A. Ladjar, "Sepatu Lokal dengan Taste Internasional," Marketing, 20 January 2016. [Online]. Available: http://marketing.co.id. [Diakses 15 December 2020].

[11] Kementrian Perindustrian Republik Indonesia - Kemenprin RI, "Perkembangan Ekspor Indonesia Berdasarkan Sektor pada Tahun 2007-2011; Pemantauan Ekspor Kelompok Hasil Industri Alas Kaki Tahun 2008-2011; Pemantauan Impor dan Ekspor Kulit, Barang Kulit, dan Sepatu/Alas Kaki Tahun 2009-2011," Kementrian Perindustrian, Jakarta, 2012.

[12] J. M. Higgins dan J. W. Vincze, Strategic Management Text amd Cases, United State: The Dryden Pass, 1993.

[13] T. J. Wheelen dan J. D. Hunger, Strategic Management, New Jersey: Prentice Hall Inc., 2000.

[14] A. Osterwalder dan Y. Pigneur, Business Model Generation: A Handbook for Visionaries, Game Changers, and Challengers, New Jersey: John Wiley \& Sons Inc., 2010. 
[15] A. Alfarisi, "Perumusan Strategi Business Model Canvas (BMC) pada Perusahaan Sandal Toyosima Singosari," Jurnal Ilmiah Mahasiswa FEB Universitas Brawijaya, vol. VIII, no. 2, pp. 1-14, 2016.

[16] W. S. Dewobroto, "Penggunaan Business Model Canvas sebagai Dasar untuk Menciptakan Alternatif Strategi Bisnis dan Kelayakan Usaha," Jurnal Teknik Industri, vol. II, no. 3, p. 2012, 215-230.

[17] Hartatik dan T. Baroto, "Strategi Pengembangan Bisnis dengan Metode Business Model Canvas," Jurnal Teknik Industri, vol. XVIII, no. 2, pp. 113-120, 2017.

[18] M. Setijawibawa, "Evaluasi Model Bisnis pada Perusahaan X Menggunakan Business Model Canvas," Agora, vol. III, no. 2, pp. 305-313, 2015.

[19] V. M. Kosasi, “Analisis dan Evaluasi Model Bisnis pada Pantai Seafood Restaurant dengan Pendekatan Business Model Canvas," Agora, vol. III, no. 2, pp. 314-323, 2015.

[20] H. Y. Ching dan C. Fauvel, "Criticims, Variations and Experiences with Business Model Canvas," International Journal of Small Business and Entrepreneurship Research, vol. I, no. 4, pp. 18-29, 2013.

[21] Syaiful, C. Furqon dan M. Sultan, “ Business Model Canvas Analysis on Cual Weaving Industry," The International Journal of Business Review (The Jobs Review), vol. I, no. 2, pp. 115-122, 2018.

[22] M. N. Dudin, G. N. Kutsuri, S. S. D. I. J. Evna Fedorova dan A. Z. Namitulina, "The Innovative Business Model Canvas in the System of Effective Budgeting," Asian Social Science, vol. XI, no. 7, pp. 290-296, 2015.

[23] M. A. Faruq dan I. Usman, "Penyusunan Strategi Bisnis dan Strategi Operasi Usaha Kecil dan Menengah pada Perusahaan Konveksi Scissors di Surabaya," Jurnal Manajemen Teori dan Terapan | Journal of Theory and Applied Management, vol. VII, no. 3, pp. 173-198, 2016.

[24] G. G. Fiseha dan A. A. Oyelana, “An Assessment of the Roles of Small and Medium Enterprises (SMEs) in the Local Economic Development (LED) in South
Africa," Journal of Economics, vol. VI, no. 3, pp. 280-290, 2015.

[25] J. C. Sort dan C. Nielsen, "Using the Business Model Canvas to Improve Investment Processes," Journal of Research in Marketing and Entrepreneurship, vol. XX, no. 1, pp. 10-33, 2018.

[26] H. A. Lee, B. DenizciGuillet dan R. Law, "An Examination of the Relationship between Online Travel Agents and Hotels: A Case Study of Choice Hotels International and Expedia.com," Cornell Hospitality Quarterly, vol. LIV, no. 1, pp. 95-107, 2013.

[27] S. Mustafa, "SMEs and its Role in Economics and Socio-Economic Development of Pakistan," IJARAFMS, vol. VII, no. 4, pp. 195-205, 2017.

[28] D. Xiaoying, L. Qianqian dan Y. Dezhi, "Business Strategy, and Information System Stategic Aligment: An Impirical Study on Chinese Firms," Tsinghua Science and Technology, vol. XIII, no. 3, pp. 348-354, 2008.

[29] A. M. Siburian, "Implementation of Business Model Canvas in Chemical Manufacturing Company PT Timuraya Tunggal," Dinasti International Journal of Economics, Finance \& Accounting, vol. I, no. 3, pp. 421-430, 2020.

[30] A. Umar, A. H. Sasongko, G. Aguzman dan Sugiharto, "Business Model Canvas as a Solution for Competing Strategy of Small Business in Indonesia," International Journal of Entrepreneurship, vol. XXII, no. 1, pp. 1-9, 2018.

[31] R. Kurniasari dan D. Kartikasari, "Penerapan Model Bisnis Kanvas terhadap Bisnis Jasa Angkut Penumpag pada PT International Golden Shipping," Journal of Applied Managerial Accounting, vol. II, no. 1, pp. 6-14, 2018.

[32] C. Lovelock dan J. Wirtz, Service Marketing: People, Technology and Strategy, United States: Pearson Education, 2011.

[33] P. Wright, Kroll, J. Mark dan J. Parnel, Strategic Management Concepts, United State: Prentice Hall Inc., 1998. 